\title{
SEX DETERMINATION IN INDONESIAN PUFFERFISH Tetraodon palembangensis Bleeker, 1852: IMPLICATION FOR AQUACULTURE AND CONSERVATION
}

\author{
Media Fitri Isma Nugraha"\#, I Wayan Subamia*), Sudarto") and Wahyu Purbowasito**) \\ ") Research Institute for Ornamental Fish \\ *) Agency for the Assessment and Application of Technology \\ (Received 27 April 2011 ; Accepted 17 June 2011)
}

\begin{abstract}
The study was based on eight specimens from a single population of Palembang pufferfish. We used a comprehensive approach comprise behavioral record, the Random Amplified Polymorphism DNA technique, exteriorly genital observation and the description of morphological coloration distinctive to recognize gender. Annotation from captivity has yielded that two genders in couple were possessed the prominent social respond in shoaling-fidelity. When the gonadal process has been released by maternal part, eggs and offspring were kept by male and there is no tolerable contact of female were given, here the female has become more cannibalism. Male adult has more brown-blackish and occasionally more flukes-dark on the half upper horizontal body it has less towering bulk and only has one genitalial hole. Female furthermore is recognizable with the present hight-bulk and has more yellow overall flukes in coloration and widely bright yellowish-dark from abdomental part to the edge of middle half of the body. Contrary, female has two genitalian holes. RAPD also has confirmed a concordance linkage what we are previously expected. We found an important mutation $176 \mathrm{bp}$ for both gender. Among the scaffold obtained, scaffold 33 is a common scaffold identified within T. palembangensis and Takifugu, it has a sufficient score bit of 36.2 with a length of nucleotide 1,758,880 bp. Moreover, this scaffold is the result from primer OPP-19 in the female of T. palembangensis, we thus can finally distinguish their sex status. The scaffold 33 might relate to the gene SOX. Our attempt may hatch a new horizon for institutional developers, aquarist and conservationist in case of surety for sustainable natural population and to ensure their stock for consumption and trading ornament requirement.
\end{abstract}

KEYWORDS: sex determination, RAPD, morphology, Tetraodon palembangensis, aquaculture, conservation

\section{INTRODUCTION}

Pufferfish Tetraodon genera has recently harbored 23 species, the group is believed to have evolved in relatively recent times from marine puffer fish and closely related with congener of Takifugu. The two pufferfish have diverged from their common ancestor between 18-30 million year (Myr) ago and from the common ancestor with mammals about $450 \mathrm{Myr}$ ago (Hedges, 2002; Jaillon et al., 2004). Some species of Tetraodon have widely occupied

\# Corresponding author. Research Institute for Ornamental Fish, Jl. Perikanan No. 13, Pancoran Mas, Depok 41152 , West Java, Indonesia. Tel.: +62 217520482

E-mail address: media.fitri@kkp.go.id 
Asian waters, the freshwater puffer fish $T$. palembangensis in fact is widely species distribution, inhabiting inland and brackish water throughout any countries except Singapore in the sister regional of Southeast Asia (Kottelat et al., 1993; Kottelat \& Widjanarti, 2005).

In recent decade, the bulk puffer $T$. palembangensis has directly been captured from nature for multi-purposes, the most frequent exploitation as for consumption and ornamental fish trade ( $\mathrm{Ng} \& \mathrm{Tan}, 1997)$. Those activities may directly decline their nature population. Another causes come from degradation habitat and demographical pressure. Despite its important value in commercial trade for villagers and lovers, sex determination by morphological features is poorly known and hatched since a long time remain unresolved debate for their production in aquaculture and conservation purpose (Devlin \& Nagahama, 2002). For aquaculture goals, it is important to state male and female in order to have an exact treatment during adult stage and prespawning phase (Aziz \& Ramadan, 1990). In aquaria and captivities, this species has seemly commenced its social fidelity while the different gender attain pre-spawning phase (Shen et al., 2007), this is only a single manual reference existent stating the putative sex differentiation two genders.

Another pathway is surgical examination of the gonads leads to identify both female and male based on gonadal morphology (Arai, 2000). Contrary, the classical method appears to be most fragile for survival after operation (Shen et al., 2007).

A recent examination can be adopted as an effective protocol by using DNA marker of RAPD to determine sex. Each marker will be present in a choice species where one species possess a unique chromosome or DNA sequence (Griffith \& Tiwari, 1993; Lessells \& Meteman, 1998).

Pufferfish have become an important model for genetic study due to their compact genome having roughly about $400 \mathrm{Mb}$. Although the presence sex of male and female in puffer fish is a conserved phenomenon, genders also have influenced by environmental fragment and genetic factor, the primary sex-determining gene is not conserved in divergent species (Capel, 2000). Unfortunately, the genome T. palembangensis is poorly studied, comparing with their congener of marine puffer of
Takifugu which has now completely been sequenced. Both pufferfish species for which a genome sequencing project has been undertaken including Tetraodon nigroviridis and Takifugu rubripes, but nowadays no information present on the mode of sex determination, the potential presence of sex chromosomes and the process of sex differentiation (Li et al., 2002).

We used the Random Amplified Polymorphism DNA technique to investigate sex determination the research is also incorporate with all sequence genome of Takifugu rubripes as a referential compact full genome. Once the PCR result and sequencing nucleotides are obtained, we thus describe the morphological feature and observation genital to have a complete character diagnostic of gender. Therefore, We are convinced that the sex determination by using RAPD in case $T$. palembangensis will reflect our basic knowledge in how to recognize the sex for further purposes.

\section{MATERIALS AND METHODS}

\section{Specimens and DNA Extraction}

The collection specimens were obtained during the visit of the third author to Palembang, South Sumetra Selatan, 2008. During his field trip, he collected some individual from one population and sent them in captivity in Depok, West Java. Since that, the nature living specimens have been developed in a separated aquarium $300-500 \mathrm{~m}^{3}$. We applied a closed recirculation system where we have advanced in our institution nearly a decade. All parameters related to behavioral of fish were recorded during 24 months in captivity. The different genitally holes of each individual was noted and the male has assummed to have one hole genitalial and female has two. A total of eight specimens were used, and two couples were used in genetic analyses. While each other individual shows a closed fidelity in foraging behavior, thus the couple has directly been placed in a separated aquarium and fed by a mixed feed comprise red worm, snail and squid. From this phase, there is no referential were known to determine their sex.

Genomic DNA were obtained from caudal tissue of each individual male and female and stored in the collection tube following the purity-ethanol conserved procedural. Extrac- 
tion was performed by DNA kit-GeneAid proto$\mathrm{col}$ and an additional Proteinase-K, final concentration $1 \mathrm{mg} / \mathrm{mL}$. DNA purification was carried out by ethanol precipitation method following (Sambrook \& Russell, 1989).

\section{PCR Amplification}

We used ten single oligonucleotide primers were:

$$
\begin{aligned}
& \text { OPP-4 : 5'GTGTCTCAGG-3’ } \\
& \text { OPP-8 : 5'ACATCGCCCA-3' } \\
& \text { OPP-12 : 5'AAGGGCGAGT-3' } \\
& \text { OPP-18 : 5'GGCTTGGCCT-3' } \\
& \text { OPA-04 : 5'AATCGGGCTG-3' } \\
& \text { OPA-10 : 5'GTGATCGCAG-3’ } \\
& \text { OPA-19 : 5'CAAACGTCGG-3’ } \\
& \text { OPB-08 : 5'GTCCACACGG-3' } \\
& \text { OPB-18 : 5'CCACAGCAGT-3’ } \\
& \text { OPC-03 : 5'AAAGCTGCGG-3' }
\end{aligned}
$$

Amplifications were performed in $25 \mu \mathrm{L}$ reaction volumes containing $5 \mu \mathrm{L}$ of DNA, 0.5 $\mu \mathrm{M}$ primers, $400 \mu \mathrm{M}$ each of dNTPs (SIGMA), 1 unit Taq polymerase (SIGMA), 1X polymerase chain reaction (PCR) buffer (SIGMA) and $1.5 \mathrm{mM}$ $\mathrm{MgCl}_{2}$. The PCR amplification was used $4 \mathrm{~min}$. at $94^{\circ} \mathrm{C}$, followed by 45 cycles consisting of $94^{\circ} \mathrm{C}$ for $1 \mathrm{~min} ., 36^{\circ} \mathrm{C}$ for $1 \mathrm{~min}$. and $72^{\circ} \mathrm{C}$ for 2 min., with a final extension at $72^{\circ} \mathrm{C}$ for $10 \mathrm{~min}$. PCR products were separated and analyzed in electrophoresis of gels agarose $1.5 \%(\mathrm{w} / \mathrm{v})$ for 50 min., 150 volt. Ethidium bromide was used 1 $\mu \mathrm{L}$ each reaction, DNA was visualized under illuminated fluorescent light and using photographed by Polaroid.

Re-amplification PCR was performed by three independent dilutions $1 x, 5 x$, and $10 x$ follows $4 \mathrm{~min}$. at $94^{\circ} \mathrm{C}$, followed by 30 cycles consisting of $94^{\circ} \mathrm{C}$ for $1 \mathrm{~min}$., $36^{\circ} \mathrm{C}$ for $1 \mathrm{~min}$. and $72^{\circ} \mathrm{C}$ for $1.30 \mathrm{~min}$., with a final extension at $72^{\circ} \mathrm{C}$ for $15 \mathrm{~min}$.

\section{Analyses of RAPD Data}

The trio sequence alignments software as Biodit ver. 07, Clustal X and NJ Plot were employed to analyze properly the sequence of chain nucleotides. We used the BLAST N to search the sequence homolog (www.blast. fugu-sg.org/cgi-bln/blast/blast2.cgi). We employed also ENSEMBLE by which its capability of detection paralogous chromosomal segment. All Scaffolds obtained as Query DNA were compared with the sister intergeneric genome of marine puffer fish Takifugu (http:// ensembl.fugu-sg.org).

\section{RESULT AND DISCUSSION}

\section{Social Pre-spawning Behavioral in Captivity}

A total of 8 fish were selected and successfully developed a long time in our institution. An adult can reach $200 \mathrm{~mm}$ in total length and attain to $2,000 \mathrm{~g}$. The feature of morphology and behavior was recorded ensuring to have empiric reference from captivity. During a long history of this species, the pronounced of morphological feature and social behavioral are little known (Kikuchi et al., 2007). This species looks unlike other species of predatory pufferfish, it doesn't prefer to warren into the substrate. It can be kept in a planted setup without problems, although plants aren't essential. Like all puffers, they are very sensitive to deteriorating water conditions, during in captivity the following water parameters measured were: Temperature $26^{\circ} \mathrm{C}-28^{\circ} \mathrm{C}, \mathrm{pH}$ 7.0-7.8.

In the course of the phase pre-spawning, we notes an important comportment in spawning that two supposed different sex seemly possessed a distinct social response of each other. While the eggs have been released by maternal, eggs and offspring then did not keep hold by male, tolerable access nor move nearer for female were given. Result suggest that female might have cannibalism for their eggs, it could be stated that the act of female as piscivorous will menace further hatching rate of the offspring's. Momentously, this is a principal key for rearing stage in aquaculture of $T$. palembangensis. It is so long time that the exposure fantastic behavioral were never known for Indonesian aquarist avoiding their interest for unique Palembang pufferfish. In many reason for sustainable effort in conservation biology, the result of this notation could also be adopted to have guaranteed the earlier stage of progeny for new generation of the species.

\section{PCR Amplification}

The reproducible DNA profile were generated from nine primers, each portion primer employed through two genders which have hypothetically been identified as male and female by the genitalia observation. 
Nine primers and their combination were used to amplify DNA product and $80 \%$ of those primer have displayed a properly incorporation with $T$. palembangensis. Those primers produced 47 band with an average 6.7 bands each sequence. Only two primers have failed to the species (primer OPP-18 and OPC-3 respectively). All primer except of two primers have failed to produce an average of 6.3 score of band pattern per primer. Therefore, we tried to resolve two failed primers but no result solution were obtained, we assume that two are running-less to the species.

All bands produced are more complex with lower of the molecular size. The only primers combination more illuminating and scoring, were selected to be sequencing, they are vary in base pair from 175-280 bp. Nine primers are present in female and three primers illuminate in male (Figure 1).

A total of seven primers were used in reamplification PCR to generate the profile RAPD from DNA of the specimens. Result of sequencing nucleotides approved that we only obtained four primers having more visible and workable for alignment, others are poorly identified and no fairly resolution were displayed. The following primers which plainly represented both gender for the next step in

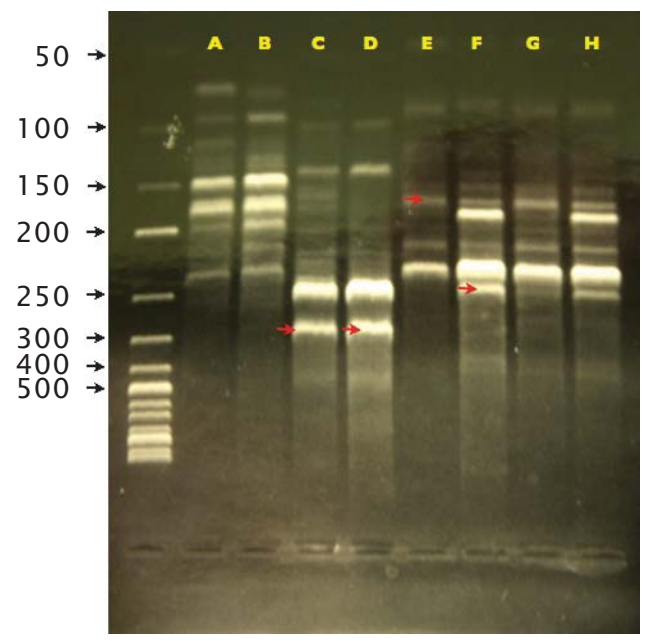

sequencing nucleotides are: OPP-12 female, OPP-1 2 male, OPP- 19 female and OPP-19 male (Table 1).

\section{Sequence Analysis}

We used Clustal $X$ for alignment nucleotide. Two of the four primers were found with the same size nucleotides 1,500 bp (OPP-19 male and OPP-19 female respectively). Contrary, those two primers possess an important mutation of 176 bp both female and male. It is seemly that the lack far nucleotides due to deletion and insertion effect during transcription process. Kikuchi et al., 2007 reported in fact the female chromosome (XX) has longer than male chromosome $(X Y)$, this is resulted from we known less recombinant occurred during meioses in the specific region, it could be also caused by the amount of mutation on the species for each gender (Kai et al., 2005; Peichel et al., 2004).

The typical phenomenon in Pelembang pufferfish is of recombinant diminution of DNA occurring both female and male. We assume that no resolution and should give by rapidly inferring of PCR method.

Using the BLASTN analyses allow to view type and position of gene in the chromosome pathway. We found of 45 scafflold which is

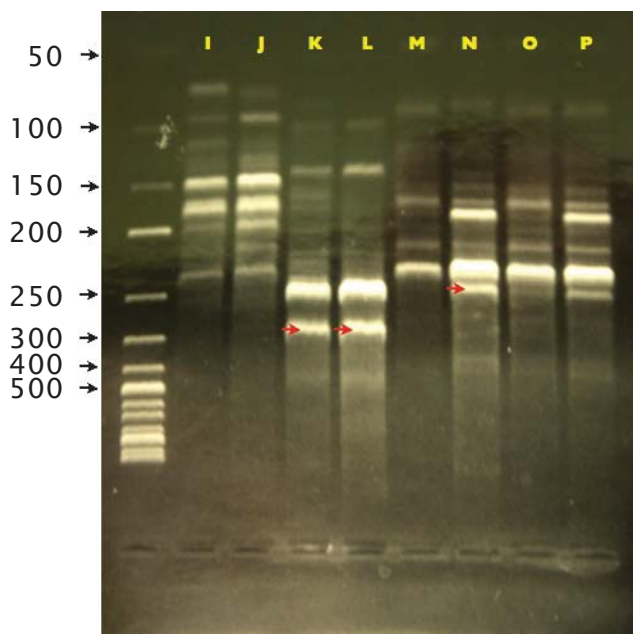

Figure 1. RAPD profile of a couple Palembang pufferfish generated by two gender primers and their paired combination, DNA Marker by FERMENTAS. [A] Male Gender primer: OPA10; [B] female OPA-10; [C] male OPA-19; [D] female OPA-19, [E] female OPP-12, [F] male OPP-12; [G] male OPP-8; [H] female OPP-8 [I] male OPP-4; [J] female OPP-4; [K] male OPB8; [L] female OPB-8; [M] male OPA-4; [N] female OPA-4; [O] male OPB-18; [P] female OPB-1 8 
Table 1. Seven primers and their combination have been chosen to generate re-amplification PCR based on exposure bands more conviction

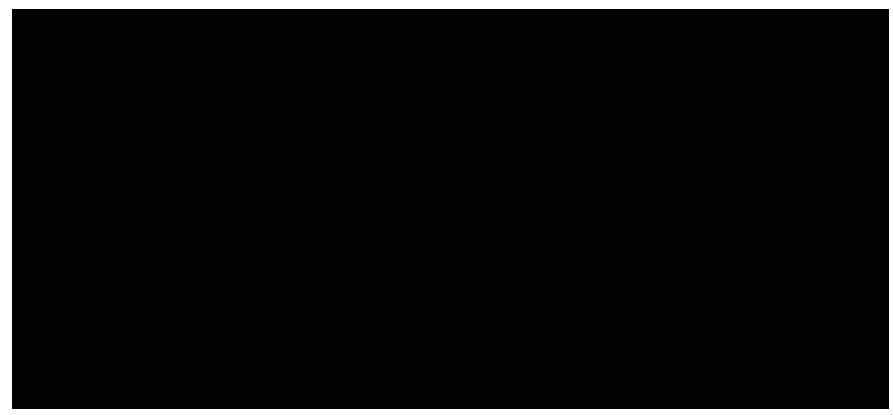

similar between Tetraodon genome and its closed gene of marine pufferfish T. rubripes which has been of model for sex determination (Koopman et al., 2004; Schartl, 2004), T. rubripes also has entirely sequenced for all its genome (Aparicio et al., 2002).

Among the scaffold obtained, scaffold 33 is an interesting scaffold identified between two congeners pufferfish, it has a sufficiency score bit of 36.2 with a length of nucleotide $1,758,880 \mathrm{bp}$. This scaffold is the result of primer OPP-19 on the female of $T$. palembangensis. The scaffold 33 might relate to the gene SOX. Brown et al. (2000) stipulated that gene SOX has firmly interconnection to the hormonal pathway which has strongly associated with sex differentiation. The producible evidence by far of primer OPP-19 in female is considerable related with precedent annotation characters that female is a far distinguishable by morphology and gentilalial evidences.

Using Ensemble analyses can be viewed the position of scaffold in the chromosome. Each scaffold is situated in its own position and well attached peer overviewed of the Scaffold 33 was pointed with high differentiation by a length $1,758,880$. Chromosomal relation and group linkage of the group, both puffer fish Tetraodon and its closest related of Takifugu have a lack of number chromosome (Takifugu, $\mathrm{n}=22$ and Tetraodon, $\mathrm{n}=21$ ). Kai et al. (2005) reported that the chromosomal are distinct due to divergence and mislaying of intron during cell division. Those diminutions of intron were notably occurred since 32 million years ago.
A basis of chromosomal comparison of two taxa, Tetraodon has extremely lost 57 of introns and 24 introns in the Takifugu, it is clearly that Tetraodon had dramatically missed their introns (Kai et al., 2005). If so, this implies a huge amount of intron gain throughout the course of eukaryotic evolution. A wide variety of eukaryotic species, including some plants, animals, fungi, apicomplexans, and perhaps excavates, shows averages of more than 5 introns per gene, implying at least hundreds of thousands of independent intron origin events (Belshaw \& Bensasson, 2006; Jeffares et al., 2006; Roy \& Gilbert, 2006).

\section{Morphological and Genital Distinctives}

Sex dimorphisms of two genders are distinguishable by the present their coloration. Our study also is based on two phase's observation. The first step, we observe their colorations whereas an individual has more visible differentiation or possess an important resemblance with their congener's couple. The second step is to continue with genital observation, once the genital feature possess one genital hole, we then are considered as male and the individual with two genital holes should be stated as female. Male is recognizable with female by the following of comparison color character (Figure 2): it has a compact towering elevate their bulk and patch. Male has a less high bulk on the top of the dorsal. The male has less yellow patch of overall body, and has more black-brownish patch from just behind tip to hypurale conjunction of caudal fin base, half of the body from mid-pectoral fin to dorsal edge exhibited several spots orange- 

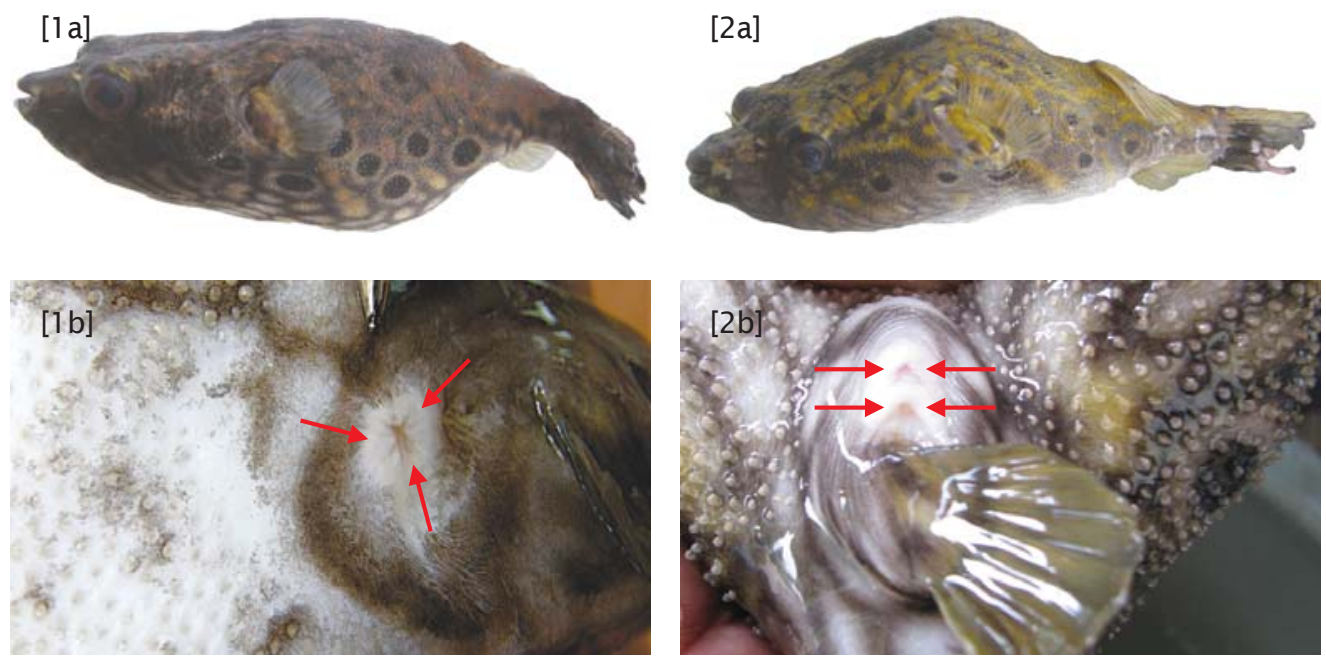

Figure 2. Distinctive of morphological features both genders female and male of $T$. palembangensis, 24 months in captivity, [a, b] upper feature is male possessing one genital hole and [c, d] lower is female with two genitals (Photo: Fortrana (2010), illustrated: Nugraha, M.F.I.)

dark in irregular form. Basal of dorsal fin, pectoral and caudal fin is also colored with minorsmall black patch with asymmetrical shape. Each black patch is contoured with a thinly yellow strip, occasionally dominated by roundly form. Male also displays a spots yellow rectangular patch, one patch frontal is most situated below edge of eyes and other patch have dispersed just behind pectoral fin ray to base of anal fin ray. The caudal of male exhibits a dark-brown with blackish strip on edge terminus of the caudal fin ray. One of the most visionary their character morphologic is the present patch circles (6 or 7). Female $T$. palembangensis is unique than their couple of male, it has abdomen more shallow but has more towering bulk than male. The female has an overall yellow fluke's coloration and widely yellowish-dark from abdomens part to the half of the body. The caudal fin is positioned more interiorly of the body and all fin rays have more yellow greenish. The spectacular character coloration distinctive is by manifesting less black patch from frontal edge of pectoral fin to the nearest edge anal fin. The black patch is oriented between 6-7 spots but less clearformed than male. Each patch is lined by a roundly strip yellowish dark to white. The female also displays 2-3 patches yellow dark just below their eyes. The eyes pupil of the female has less bright orange than male.

\section{Implication for Aquaculture and Conservation}

The trio combination characters as morphological feature coloration, observation genital and RAPD analysis can now follow us to recognize both genders of the T. palembangensis. These parallels observations have yielded a novel rapid protocol in identification of sex mode. Thus, the result also could be easily adopted how to identify an adult for their aquaculture purpose. It is important to note that environmental factors including temperature, $\mathrm{pH}$, density and social interactions could also influence the sex ratio in gonochoristic species (Abucay et al., 1999; Baroiller \& D'Cotta, 2001).

As the precedently reported, conservation status of T. palembangensis is little known due to some reasons. It is seemly that there is no conservation act will rescue their generation. With a monthly trading of a thousand individuals, even more for consummation, that collected activity unfortunately comes from the nature. Conversely, the wild population will face a serious consequence at the nearest time. Here we suggest an efficiency pathway with a great desire that the capture from the nature could be cut down and it could be moderately served both villagers and aquaria's demand. Domestication trial for new candidate 
species is needed. This effort is only an endeavor effort in how to obtain sustainable generation. While the domestication trial is given well result, we then could continue to the second step of ex-situ and in-situ conservation.

Two outcomes are previously expected, domestication protocol by which sex determination is well recognizable, it could aid the villagers and institutional (Fontaine et al., 2009), and to answer both demand of consummation and aquaria. As freshwater habitat was partly incorporating with demographic activities, Brown \& Charles (1998) proposed four steps for conserving habitat, we also have enriched with additional logic application for conservation biology and ecosystem. First is the conservation rating of a particular site and its biological value are a measure of how well it satisfies certain. Second, the conservation value of a site and biological species is that site's conservation rating converted to a money value by expressing it as a percentage (low, medium, or high) of the average assessed value of habitat and their biotope in the community. Third, the market value of the site is the price that it would bring in an open and competitive market, according to its highest and best economic use and assuming that it is not restricted for conservation purposes. Fourth, the replacement value of a property is equal to its conservation added value to its market value, thereby incorporating both the economic value of the property as well as its public interest value. The replacement value may be used to estimate the relative worth of a potential conservation purchase, or as a starting point for negotiations to determine compensation for existing conservation land in the event of a taking by another unit of government, this point is never reliable for conservation biology by its important present for the next generation.

\section{CONCLUSION}

This study reflects our knowledge in what we had never known for entirely Indonesian developer in aquaculture, aquaria and conservation. By capturing and trading regularly and no act to ensure their stock in nature, therefore Indonesian freshwater pufferfish will face a dramatically population size and menace for extinction in short decade. In raison to keep the existent this unique species, result of our study might be served for villager, aquacultures, institutional authority, aquarist and conservationist. This comprehensive study also provides how to recognize their gender for spawning purpose. In three domains mentioned above, sex determination is only one of the main curiosity obstacle in identification the candidate progenitors. Finally, we can view that male has more brown-black and dark and possessed one only genital hole. The female is recognizable with an overall yellow bright coloration and it has two holes of genital, lying continuously to the basal edge of anal fin ray. RAPD has also confirmed a concordance linkage what we are previously though by featuring genital and coloration distinctive. A total of ten primers were used, two of them failed. Four bands specific were found which are referable for analysis of sex determination. Ensemble analyses revealed one scaffold (scaffold 33), referred in detection of female which was allied with marker OPP-19 female of $1.758 .880 \mathrm{bp}$. We are convinced that all the heritage of Indonesian candidate species for aquaculture should be domesticated in case for responding the demand from various interest communities.

\section{ACKNOWLEDGMENT}

We would like to thank the colleague in domestication trial, Mr. Sadudin for his support in development this bizarre species during in captivity at BRBIH-Depok. We also acknowledge the help of two anonymous reviewers during the work construction on this manuscript. This work is a part of the main desire of our institution to domesticate Indonesian native species for aquaculture, aquaria and conservation goals. Photos are provided by Danio Fortrana and illustrated by Media Fitri Isma Nugraha.

\section{REFERENCES}

Abucay, J.S., Mair, G.C., Skibinsky, D.O.F., \& Beardmore, J.A. 1999. Environmental sex determination: the effect of temperature and salinity on sex ratio in Oreochromis niloticus L. Aquaculture, 173: 21 9-234.

Aparicio, S., Chapman, J., Stupka, E., Putnam, N., \& Chia, J.M. 2002. Whole-genome shotgun assembly and analysis of the genome of Fugu rubripes. Science, 297: 1301-1310.

Arai, K. 2000. Genetic improvement of aquaculture finfish species by chromosome manipulation techniques in Japan. Aquaculture, 197: 205-228. 
Aziz, A. \& Ramadan, A.A. 1990. Sexuality and hermaphroditism in fishes: I. Synchronous functional hermaphroditism in the serranid fish Serranus scriba L. Folia Morphol., 38: 86-100.

Baroiller, J.F. \& D'Cotta, H. 2001 . Environment and sex determination in farmed fish. Comparative Biochemistry and Physiology Part C, 130. 399-409.

Belshaw, R. \& Bensasson, D. 2006. The rise and fall of introns. Heredity, 96: 208-213.

Brown, C.W., Houston-Hawkins, D.E., Woodruff, T.K., \& Matzuk, M.M. 2000. Insertion of Inhbb into the Inhba locus rescues the Inhba-null phenotype and reveals new activin functions. Nat. Genet., 25: 453-457.

Brown, P.J. \& Charles.1998. A Methodology for Valuing Town Conservation Land. Working Paper Lincoln Institute of Land Policy.

Capel, B. 2000. The battle of the sexes. Mech. Dev., 92: 89-103.

Devlin, R.H. \& Nagahama, Y. 2002. Sex determination and sex differentiation in fish: an overview of genetic, physiological, and environmental influences. Aquaculture, 208: 191-364.

Fontaine, P., Legendre, M. Vandeputte, M., \& Fostier, A. 2009. Domestication de nouvelle d'especes et developpement durable de la pisciculture. Cah Agric., 18: 2-3.

Griffith, R. \& Tiwari, B. 1993. The isolation of molecular genetic markers for the identification of sex. Proc. Natl Acad. Sci. USA, 90: $8,324-8,326$.

Hedges, S.B. 2002. The origin and evolution of model organisms. Nature Rev. Genet., 3: 838-849.

Jaillon, O., Aury, J.M., Brunet, F., Petit, J.L., Thomann, N.S., Mauceli, E., Bouneau, L., Fischer, C., Costaz, C.O., Bernot, A., Nicaud, S., Jaffe, D., Fisher, S., Lutfalla, G., Dossat, C., Segurens, B., Dasilva, C., Salanoubat, M., Levy, M., Boudet, N., Castellano, S., Anthouard, Jubin, C., Castelli, N., Katinka, M., Vacherie, B., Bie'mont, M., Skalli, Z., Cattolico, L., Poulain, J., Berardinis, V., Cruaud, C., Duprat, S., Brottier, P., Coutanceau, J.P., Gouzy, J., Parra, G., Lardier, G., Chapple, C., McKernan, K.J., McEwan, P., Bosak, S., Kellis, M., Volff, J.N., Guigo, R., Zody, M.C., Mesirov, J., Toh, K.L., Birren, B., Nusbaum, C., Kahn, D., Rechavi, M.R., Laudet, V., Schachter, V., Quertier, F., Saurin, W., Scarpelli, C., Wincker, P., Lander,
E.S., Weissenbach, J., \& Crollius 1, H.R. 2004. Genome duplication in the teleost fish Tetraodon nigroviridis reveals the early vertebrate proto-karyotype. Nature, 31: 946-957.

Jeffares, D.C., Mourier, T., \& Penny, D. 2006. The biology of intron gain and loss. Trends Genetic, 22: 16-22.

Kai, W., Kikuchi, K., Fujita, M., Suetake, H., Fujiwara, A., Yoshiura, Y., Ototake, M., Vekatesh, B., Miyaki, K., \& Suzuki, Y. 2005. A genetic linkage map for the tiger pufferfish, Takifugu rubripes. Genetics, 171: 227-238.

Kikuchi, K., Kai, W., Hosokawa, A., Mizuno, N., Suetake, H., Asahina, K., \& Suzuki, Y. 2007. The Sex-Determining Locus in the Tiger Pufferfish, Takifugu rubripes. Genetics, 175 : 2,039-2,042.

Kottelat, M. \& Widjanarti, E. 2005. The fishes of Danau Sentarum National Park and the Kapuas Lakes area, Kalimantan Barat, Indonesia. The Raffles Bulletin of Zoology Suppl., 13: 139-173.

Kottelat, M., Whitten, A.J., Kartikasari, S.N., \& Wirjoatmodjo, S. 1993. Freshwater fishes of Western Indonesia and Sulawesi. Periplus Editions, Hong Kong, 221 pp.

Koopman, P., Schepers, G., Brenner, S., \& Venkatesh, B. 2004. Origin and diversity of the SOX transcription factor gene family: genome-wide analysis in Takifugu rubripes. Gene, 328: 177-186.

Lessells, C.M. \& Mateman, A.C. 1998: Sexing birds using random amplified polymorphic DNA (RAPD) markers. Mol. Ecol., 7: 187-195.

Li, Y., Hill, J.A., Yue, G.H., Chen, F., \& Orban, L. 2002. Extensive search does not identify genomic sex markers in Tetraodon nigroviridis. J. of Fish Biology, 61: 1,3141,317 .

Ng, P.K.L. \& Tan H.H. 1997. Freshwater Fishes of Southeast Asia: potential for the aquarium fish trade and conservation issues. Aquarium Sciences and Conservation, I: $79-90$.

Peichel, C.L., Ross., J.A., Matson, C.K., Dickson, M., \& Grimwood, J. 2004. The master sexdetermination locus in threespine sticklebacks is on a nascent $Y$ chromosome. Curr. Biol., 14: 1416-1424.

Roy, S.W. \& Gilbert, W. 2006. The evolution of spliceosomal introns: patterns, puzzles and Progress. Nat. Rev. Genet., 7: 211-221. 
Sambrook, J. \& Russell, D.W. 1989. Molecular cloning. A Laboratory manual. CSHL press.

Schartl, M. 2004. A comparative view on sex determination in medaka. Mech. Dev., 121: 639-645.
Shen, X., Cui, J., Yang, G., Gong, Q., \& Gu, Q. 2007. Expression Detection of DMRTs and Two sox 9 Genes in Takifugu rubripes (Tetraodontidae, Vertebrata). J. Ocean Univ. China (Oceanic and Coastal Sea Research), 6(2): 182-186. 